\title{
Fotografias do impossível - O limiar nas fotografias de Hans Breder e de Walter Tochtrop
}

\section{Photographing the Impossible - The threshold on photographs made by Hans Breder and Walter Tochtrop}

\author{
Fotografías del Imposible - \\ El umbral en las fotografías de Hans Breder
y de Walter Tochtrop \\ El umbral en las fotografías de Hans Breder
y de Walter Tochtrop
}

Isadora de Vilhena Barretto *

http://dx.doi.org/10.22409/poiesis.2033.375-394

\begin{abstract}
RESUMO: Neste artigo, propõe-se o aprofundamento teórico do conceito de limiar a partir da análise das obras de Hans Breder e do fotógrafo brasileiro Walter Tochtrop. Primeiramente, a ideia de dissolução e deformação são analisadas a partir do pensamento de Gaston Bachelard e de suas reflexões a respeito dos arquétipos da água e do ar. Posteriormente, discute-se a presença do espelho enquanto elemento artístico, evocando a ideia de heterotopia desenvolvida por Michel Foucault. A partir disso, propõe-se o caráter reflexivo, crítico e criativo das zonas liminares, compreendo-as como um possível espaço de transformação e engendramento de novas realidades.
\end{abstract}

PALAVRAS-CHAVE: limiar; fotografia; Tochtrop; Breder

\footnotetext{
* Isadora de Vilhena Barretto é mestre em Memória Social pela Universidade Federal do Estado do Rio de Janeiro (PPGMS-UNIRIO) e graduada em Comunicação Social pela Universidade Federal do Rio de Janeiro (ECO-UFRJ). E-mail: isadora.barretto@gmail.com. Orcid: https://orcid.org/0000-0001-7763-4878
} 
ABSTRACT: In this article, it is proposed the theoretical deepening of the concept of threshold from the analysis of the works of Hans Breder and the Brazilian photographer Walter Tochtrop. First, the idea of dissolution and deformation are analyzed from Gaston Bachelard's thought and his reflections on the archetypes of water and air. Subsequently, the presence of the mirror as an artistic element is discussed, evoking the idea of heterotopia developed by Michel Foucault. From this, the reflexive, critical and creative character of the liminal zones is evoked, understanding them as a possible space for transformation and engenderment of new realities.

KEYWORDS: threshold; photography; Tochtrop; Breder

RESUMEN: En este artículo, se propone la profundización teórica del concepto de umbral a partir del análisis de las obras de Hans Breder y del fotógrafo brasileño Walter Tochtrop. En primer lugar, la idea de disolución y deformación se analiza a partir del pensamiento de Gastón Bachelard y de sus reflexiones acerca de los arquetipos del agua y del aire. Posteriormente, se discute la presencia del espejo como elemento artístico, evocando la idea de heterotopía desarrollada por Michel Foucault. A partir de eso, se evoca el carácter reflexivo, crítico y creativo de las zonas liminares, comprendiendo como un posible espacio de transformación y engendramiento de nuevas realidades.

PALABRAS CLAVE: umbral; fotografía; Tochtrop; Breder 


\section{Fotografias do impossível - O limiar nas fotografias de Hans Breder e de Walter Tochtrop}

Suponho que todo ser humano já tenha passado pela experiência de olhar por um longo período de tempo para um objeto. Imaginemos um objeto comum, uma mesa ou uma cadeira, por exemplo. Podemos pensar em uma cadeira posta em uma sala de estar. Primeiro, olha-se para a cadeira e entende-se que aquilo é uma cadeira. Segundo o Dicionário Aurélio, um "assento de costas para uma pessoa só", ou ainda, um objeto produzido pelo homem cuja utilidade se faz no sentar. Algum tempo após esse reconhecimento inicial, em seguida, passamos a associar a cadeira ao que ela nos faz lembrar. Histórias que tivemos com ela, coisas com as quais ela se parece, pessoas que com ela já tiveram uma relação. Em suma, ativa-se em nós o modo como ela nos remete a outros objetos, pessoas e momentos, resgatando lembranças presentes em nossa memória. Com mais algum tempo de observação, contudo, um fenômeno peculiar pode ocorrer. Em vez de relacionarmos a cadeira a um conceito ou a um referente, começamos a visualizá-la não pelo que ela nos representa, mas como uma coisa outra. Algo sem passado, como um objeto novo, visto pela primeira vez. Passamos, então, a, lentamente, analisar seus contornos. Investigamos suas formas, a matéria com que é feita, o ritmo de sua composição, até o momento em que decompomos sua unidade por completo e, 
voltando-nos novamente a ela, temos uma sensação de deformação. Olhamos por tão longo tempo e com tamanha intensidade para a cadeira que, curiosamente, ela para de nos fazer sentido. A cadeira, então, não se apresenta mais somente como uma cadeira um objeto conhecido, apreendido, previsível, de destino dado -, mas como algo que para nós passa a ser, curiosamente, um objeto desconhecido.

A experiência de olhar por um longo período de tempo para um objeto - no caso descrito acima, tivemos como exemplo uma cadeira, mas o experimento poderia ser feito com qualquer outra coisa - parece trazer a mesma sensação que podemos perceber ao observar algumas fotografias específicas a serem analisadas neste artigo. São fotografias dos artistas Hans Breder e Walter Tochtrop; fotografias de limiar, que fogem ou questionam aquilo que consideramos definido e delimitado, parecendo vacilar diante do modo como tradicionalmente recebemos ou classificamos algo. Se, em todo objeto como a cadeira na sala de estar - há algo de impreciso capaz de abalar as estruturas do que temos como estabelecido, nas obras de tais artistas essa característica aparece na superfície, como se nelas fosse um tema basilar e principal. A proposta aqui, então, é que nelas imerjamos. Que as questionemos e as analisemos para a produção de algumas reflexões: o que essas fotografias podem dizer mais profundamente sobre o limiar? Quais elementos se relacionam com esse fenômeno e para que lugares ele nos leva?

Dito isso, comecemos então por uma imagem. Dois corpos deitados sobre uma mesa segurando, cada um, um espelho que os refletem em direção à câmera. Os genitais estão cobertos um pelo corpo do outro e não é possível compreender se são do sexo masculino ou feminino. Somente as pernas aparecem, deixando para o outro lado do espelho as cabeças e os troncos. Corpos neutros, sem marcas, híbridos e genéricos. Poderíamos concebê-los como corpos universais. O ângulo dos espelhos faz com que esses corpos refletidos se multipliquem, criando, a partir disso, duas visões possíveis. Em uma delas, a cena de uma enorme quantidade de corpos entranhados uns nos outros - uma possível cena de orgia, um bacanal. Em outra, a ideia de um corpo único. Um corpo fusionado e irreal, confusamente formado, sem início nem fim. Nos dois casos, a sensação passada é a de um cenário de realidade inventada, em que os espelhos não parecem ser colocados

Poiésis, Niterói, v. 20, n. 33, jan./jun. 2019. 
para separar realidade de ilusão, real de virtual, mas justamente para dissolver e desorientar, criando realidades produzidas - ou reveladas - por um jogo singular de distribuição de olhares.

É curioso dizer que a ideia de dissolução nos trabalhos de Hans Breder - autor da fotografia acima descrita - não parece se manifestar somente pelo uso do espelho, mas também a partir de outro elemento: a água. Os mesmos corpos universais e fragmentadamente espelhados também são vistos com frequência em seus trabalhos flutuando, boiando ou caídos em rios e praias. Corpos sólidos navegando em ambientes aquosos. Sobre eles, o pensamento de Gaston Bachelard pode nos apontar algo de interessante. Em A água e os sonhos (1997), o autor diz que a deformação das formas é o que nos permite visualizar a matéria escondida sob a figura dos objetos. Sua fixação, para ele, faz com que o mundo se disperse em coisas díspares, em objetos imóveis e inertes, objetos que, por separação, tornam-se estranhos a nós mesmos, tornando nossa alma, em consequência, deficiente do que ele chama de imaginação material.

Para o autor, existiriam duas formas distintas de se imaginar. Na imaginação formal, ligada ao sentido da visão, à figura do olho e ao ato de ver, a ação imaginativa seria feita por meio de um exercício constante de abstração, baseada em um modelo teórico matemático e lógico-empírico ligados à tradição aristotélica, cartesiana e positivista das ciências naturais. (GOMES, 2015) Nela, o homem que imagina seria obrigado à produção de um distanciamento, tornando-se passivo e ocioso ao separar-se do mundo que o rodeia. Na imaginação material, ligada, em contrapartida, ao sentido do tato, à figura das mãos e ao ato de sentir, o homem seria, por outro lado, um agente ativo e em conflito com os elementos do mundo, provocando-o e modelando-o, na mesma medida em que também é provocado por sua aparente solidez. A imaginação material, portanto, funcionaria como uma construção, como uma concretização criativa feita a partir de elementos do próprio mundo, ao mesmo tempo em que com ele se movimenta. Uma real materialização do imaginário, ou, em outras palavras, o próprio imaginário, materializado. 
Marcelo Gomes (2015) diz que, para Bachelard, o elemento, o arquétipo da água se confunde com a própria imaginação material, como se ela fosse quase seu substrato, o plasma onde a imaginação é produzida. Para o filósofo francês, a água, "agrupando as imagens, dissolvendo as substâncias, ajuda a imaginação em sua tarefa de desobjetivação. Proporciona um tipo de sintaxe, uma ligação contínua das imagens, um suave movimento das imagens que libera o devaneio preso aos objetos". (BACHELARD, 1997, p. 13) Sendo ao mesmo tempo fluida, solvente, homogênea e coesa, a água para ele ocuparia um lugar intermediário, uma posição limiar entre o sólido e o gasoso, entre a materialidade compacta da terra e a suave leveza do ar. (BACHELARD, 1997) A partir do pensamento de Bachelard, poderíamos abordar os corpos espelhados, flutuantes, produzidos por Hans Breder, não somente como corpos, mas como corpos aquosos, em processo de dissolução, postos em um estado físico próprio que os abririam à maleabilidade típica da imaginação.

É interessante ressaltar que Hans Breder dedicou parte de sua vida à fundação de um programa de intermídias na universidade em que trabalhava - a School of Art \& Art History, na Universidade de Iowa - e, como professor de arte, ficou conhecido como alguém que se desafia a quebrar as formas tradicionais de ensino, combinando disciplinas como pintura, escultura, instalação, performance, música, filme, fotografia e vídeo. Com uma forte verve interdisciplinar - ou, ainda, transdisciplinar -, suas obras, e principalmente sua série Body/Sculpture, são vistas e comentadas como trabalhos que questionam a relação entre espaço, corpo e a fragmentação das formas, e a fronteira entre fotografia, escultura e performance. Um trabalho, portanto, sobre limites e que provoca seus próprios limites, posicionando ambos em uma espécie de "entre" das coisas.

\footnotetext{
Seu trabalho procura articular e evocar um poder inefável além da razão e da desrazão. Contra 0 materialismo monumental da cultura ocidental, durante as últimas seis décadas, a sensibilidade "entremídia" de Breder foi expressada nas relações entre pintura, escultura, fotografia, música, instalação, vídeo e filme - cada expressão um convite à liminaridade subversiva e à transcendência momentânea. 0 trabalho de Breder dissolve fronteiras e manipula a percepção, às vezes atraindo, às vezes chocando o observador, permitindo a ele uma experiência de liminaridade a partir da qual um reino de pura possibilidade pode surgir. (COHEN, 2018)
}

Poiésis, Niterói, v. 20, n. 33, jan./jun. 2019. 
O trabalho de Breder lembra também o de outro artista: o brasileiro Walter Tochtrop. Assim como em Breder, suas imagens parecem falar sobre uma tentativa de junção de dois mundos distintos. Giro d'alma, por exemplo, mostra uma série de fotos de uma mulher fantasmagórica, quase transparente, espectral, multiplicada por meio de uma possível dupla exposição; Night Memories, feita em conjunto com o artista Jean Guimarães, revela esqueletos de luzes, almas assombradas e espíritos pensativos deslocados de seus próprios corpos. Ruptures exibe uma sequência de fotografias em que a figura de um homem é processualmente quebrada, partindo de seu rosto parcialmente exposto atrás de uma máscara até uma imagem de caráter próprio, produzido a partir de partes humanas visualmente fragmentadas. Todas as três séries apresentam a imagem de algo inacessível, invisível, imaterial, algo que desafia a capacidade de nossos olhos. São imagens fantásticas, irreais, por vezes com um curioso aspecto de sonho.

Se, de acordo com as ideias de Bachelard, as fotografias de Hans Breder aludiriam ao arquétipo da água, as imagens de Walter Tochtrop, por sua vez, parecem referir-se a um elemento mais etéreo, incorpóreo, impalpável. Parecem soar como tentativas materiais de contato com algo fora do campo da matéria, ou, em outras palavras, uma tentativa de materialização daquilo que já é, em si, desmaterializado. Sobre isso, Bachelard (2001) pode auxiliar novamente ao elaborar outro tipo possível de imaginação, essa, dessa vez, ligada ao elemento ar. De acordo com o autor, se a imaginação material remeteria à materialização do imaginário, existiria uma outra que corresponderia, por sua vez, ao que ele chama de volatização quântica dos objetos concretos, relacionando-se aos movimentos desmaterializantes e à criação de seres ditos "aéreos". A esse tipo de imaginar, ele intitula imaginação dinâmica do movimento e trabalha-o em seu livro $O$ ar e os sonhos. Sobre a obra, Marcelo Gomes comenta:

0 livro OAreosSorhosé dedicado à imaginação dinâmica do movimento. Bachelard recolhe imagens aéreas: horizontes sem fim, espaços abertos, imensidões celestes, sonhos em vôo e de queda, árvores gigantescas, mas principalmente do movimento desmaterializante e da verticalização do tempo: lampejos da eternidade, instantes absolutos em que o mundo para, momentos de sincronicidade em que elementos diversos e até contrários formam uma unidade. (GOMES, 2015, p. 06)

Poiésis, Niterói, v. 20, n. 33, jan./jun. 2018. 

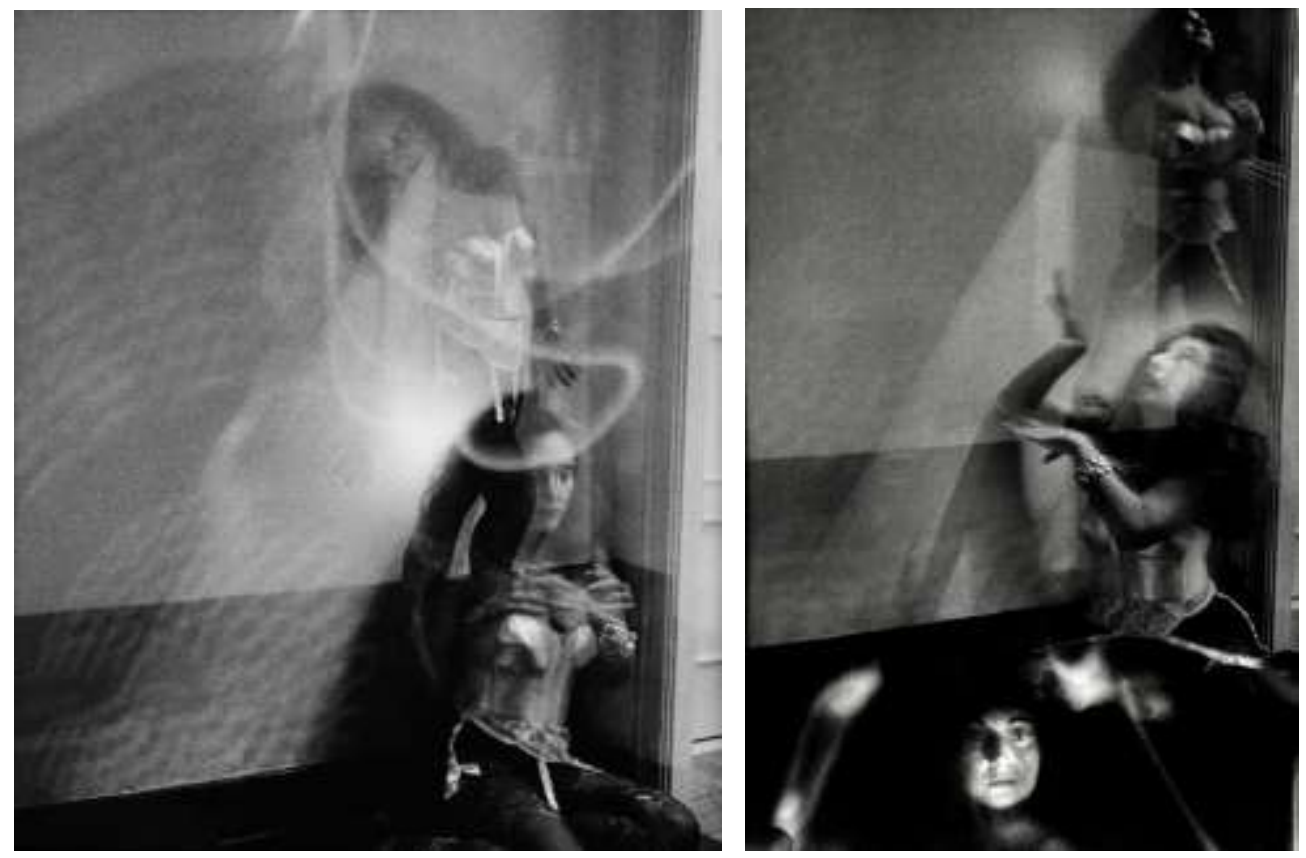

Fig. 1 - Walter Tochtrop, Giro d'Alma, 1989.

fotografia analógica

Poiésis, Niterói, v. 20, n. 33, jan./jun. 2019. 


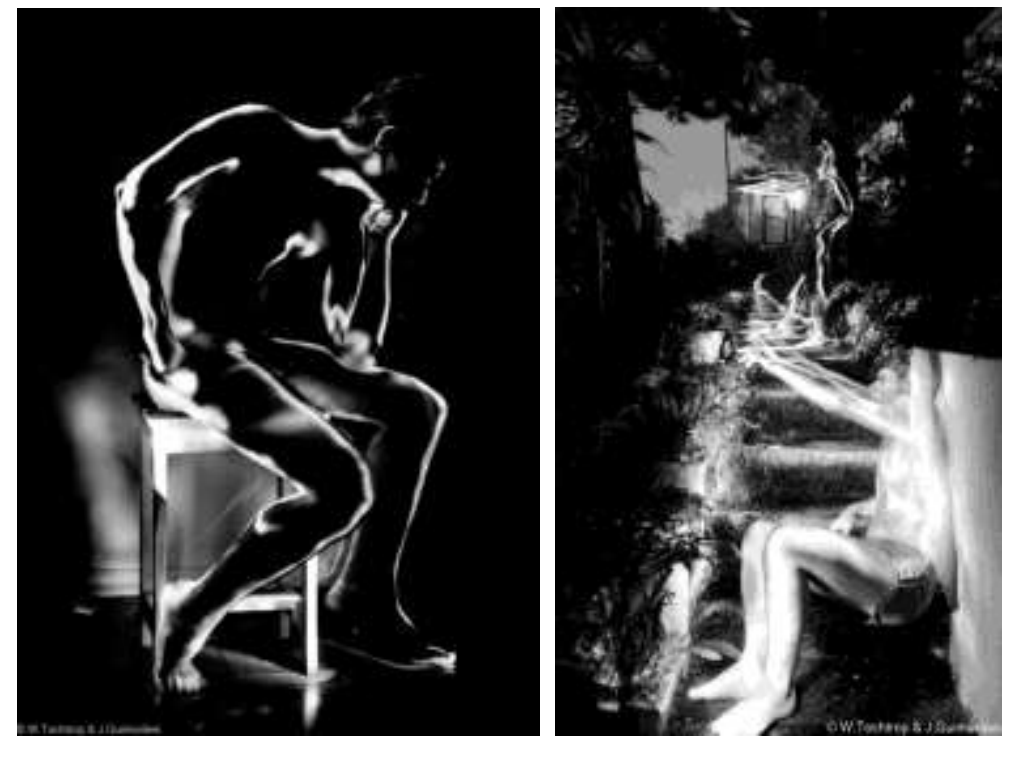

Fig. 2 - Walter Tochtrop e Jean Guimarães, Night Memories, 1987. fotografia analógica 


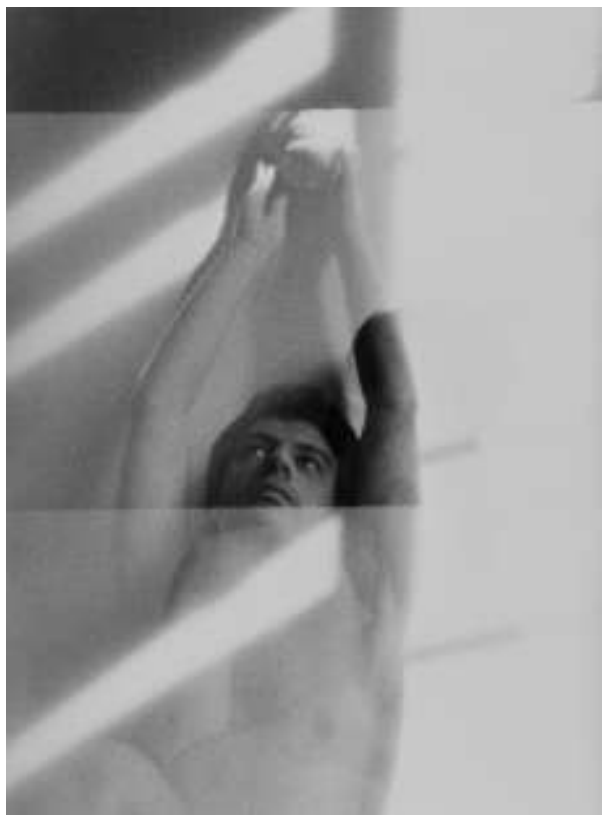

Fig. 3 - Walter Tochtrop, Ruptures, 1989. fotografia analógica

Poiésis, Niterói, v. 20, n. 33, jan./jun. 2019. 


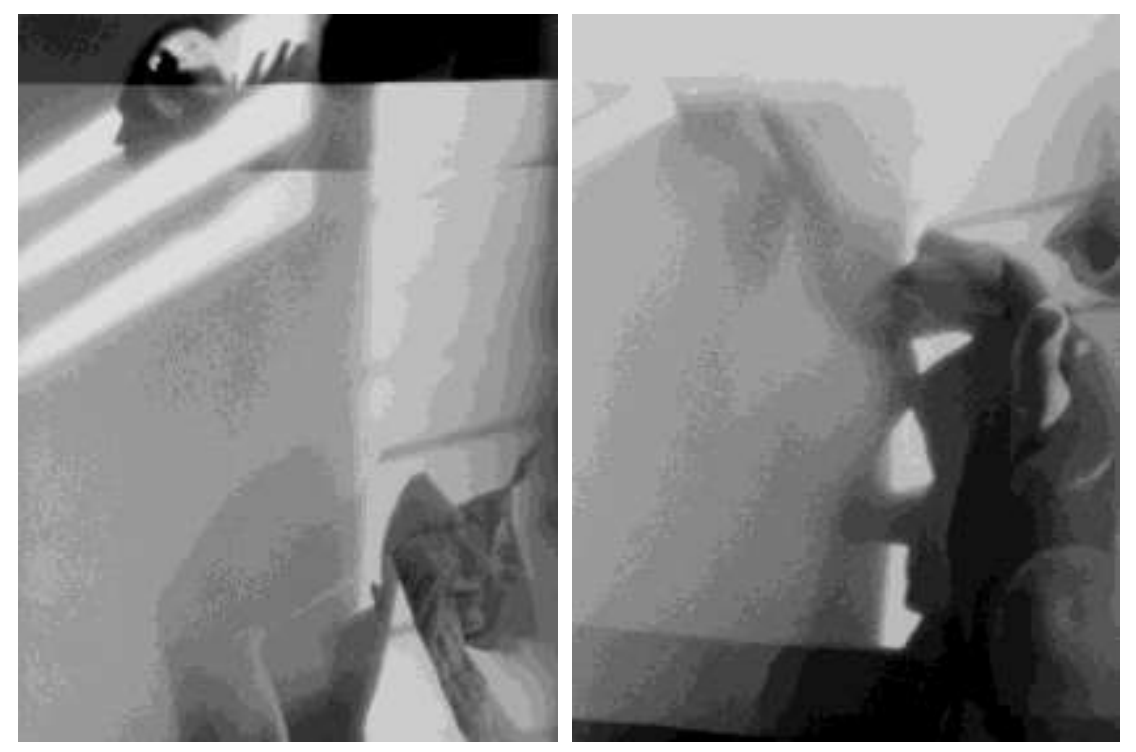

Fig. 4 - Walter Tochtrop, Ruptures, 1989. fotografia analógica

Poiésis, Niterói, v. 20, n. 33, jan./jun. 2018. 
Segundo Gomes, "nas imagens aéreas de movimento, o mundo dos objetos se torna um universo de relações" (2005, p. 6), em que frequências vibracionais diversas, tempos diversos podem ser postos em um mesmo espaço. Ora, o movimento desmaterializante e a verticalização do tempo são o que apresentam as imagens de Tochtrop: imagens que, por um lado, congelam instantes efêmeros, e por outro, sincronizam diferentes perspectivas e tempos em um único espaço temporal, um único quadro fotográfico. Suas fotografias são, ao mesmo tempo, uma composição de ângulos e passados diversos, e a tentativa de concretização de elementos incorpóreos, intangíveis, ou, na verdade, de acordo com Bachelard, a desmaterialização da matéria feita a partir da fixação, da eternização, da perpetuação do próprio movimento, criando a partir de elementos de nossa própria realidade um mundo completamente outro, fantástico, obscuro, quase abstrato.

É intrigante perceber dois aspectos presentes nas obras desses dois artistas que podem nos trazer informações de grande relevância para compreendermos melhor como nelas ocorre o fenômeno do limiar. Um deles é certa vontade de retratar algo da ordem do "irretratável" - não à toa, são elas relacionadas à noção de imaginação. Da ideia de irretratabilidade, podemos considerar duas possibilidades interpretativas. Por um lado, pode significar elementos em si incorpóreos, imateriais; e por outro, algo que ainda não existe na realidade, algo ainda não vivenciado, algo, em suma, encarado como uma potência, como uma expectativa ainda não concretizada ou, por que não, como uma possibilidade futura, em latência e, por isso mesmo, ainda incerta. Quanto a esta última, podemos inferir que os corpos expostos neste artigo também se encontram em um estado intermediário, em um estado próprio, um estado que talvez seja o próprio movimento de transformação. São corpos frágeis, efêmeros, fugidios, transitórios, oscilantes, inconstantes, ainda sem classificação. Poderiam ser considerados, portanto, retratos de corpos em processo, cuja forma ainda não chegou a ser atingida. A visão fixada de algo que ainda está por vir, ou, em outras palavras, verdadeiros corpos abertos, em estado de devir.

Mas como, afinal, retratar o irretratável? É exatamente aqui que o caráter liminar do meio fotográfico pode também ser constatado. Embora, enquanto ferramenta, a fotografia seja

Poiésis, Niterói, v. 20, n. 33, jan./jun. 2019. 
comumente utilizada como uma forma de se registrar uma realidade passada, tais obras utilizam-na não para o testemunho de um mundo já visto, memorizado - nem mesmo, em alguns dos casos, para um mundo visível e memorizável -, mas para a criação de outros mundos, de outras experiências, de outros corpos possíveis. Isso significa que há nelas uma intenção de se produzir um tipo de fotografia que não se limite à representação da realidade ou de um passado vivido, mas o fazem, curiosamente, utilizando-se de um meio cujas características remetem inevitavelmente a uma conservação de memória, a uma retenção de tempo, a uma percepção de algo real que já passou. Tais fotos, portanto, parecem querer ultrapassar a memória em seu âmbito de conservação, em sua interpretação simplória de registro, representação, questionando-a, manipulando-a, abrindo-a e utilizando-a, enfim, para o criar. Elas são geradas a partir de restos de passado, de dados memoriais, para a produção de um novo. Assim, da mesma forma como podem ser concebidas como retratos, reproduções, são elas também invenções. Produções feitas de passado, para serem estranhamente experimentadas como presença e ato. Como corpos inventados, corpos-invenções.

E como exatamente isso é feito? Embaralhando, brincando com o visível, deformando, deslocando e distorcendo dados da memória. É este o segundo aspecto presente nas obras de Breder e Tochtrop e aquilo que faz com que o conteúdo de suas fotografias sejam, também, liminares. Em relação a isso, é impossível deixar de constatar que tanto o espelho quanto a água são elementos ligados à distorção que também aparecem em seus trabalhos com frequência. No primeiro caso, mesmo nas fotografias de Walter Tochtrop, cujos corpos apontam para uma espécie de dissolução distinta, de caráter volátil, suas imagens, ainda assim, exibem um desfazer-se, um desmanchar, uma diluição de suas fronteiras e delimitações, de seu estado corpóreo em algo que não é exatamente aquoso, mas igualmente fluido. Da mesma maneira, os corpos fragmentados da primeira fotografia de Breder não estão exatamente solúveis, mas, no seu caso, parecem quebrados, rompidos, decompostos, remetendo somente a uma outra modalidade possível de um processo de desobjetivação. Do sólido para o líquido, do líquido para o gasoso, do concreto para o fragmentado, todos eles apresentam um tipo de distorção que os deslocam de seu posto de certeza, de solidez interpretativa, fixa, definida, definitiva.

Poiésis, Niterói, v. 20, n. 33, jan./jun. 2018. 
Em relação ao espelho, a distorção parece ser apresentada tanto de maneira concreta e imagética quanto de modo mais simbólico e subjetivo. Michel Foucault, aqui, nos auxilia ao propor que o espelho, a partir de um espaço virtual, é capaz de refletir em nós uma diferença. Em outras palavras, o espelho, para ele, provoca em nós um estranhamento, uma interferência, uma reflexão ao produzir a partir da criação de um outro lugar, de um outro espaço, o confronto com nós mesmos, com nossa imagem, nosso corpo, ou, por que não também, com nossa crível identidade.

0 espelho, afinal, é uma utopia, pois é um lugar sem lugar. No espelho, eu me vejo lá onde não estou, em um espaço irreal que se abre virtualmente atrás da superfície, eu estou lá longe, lá onde não estou, uma espécie de sombra que me dá a mim mesmo minha própria visibilidade, que me permite me olhar lá onde estou ausente: utopia do espelho. Mas é igualmente uma heterotopia, na medida em que o espelho existe realmente, e que tem, no lugar que ocupo, uma espécie de efeito retroativo; é a partir do espelho que me descubro ausente no lugar em que estou porque eu me vejo lá longe. A partir desse olhar que de qualquer forma se dirige para mim, do fundo desse espaço virtual que está do outro lado do espelho, eu retorno a mim mesmo e a me constituir ali onde estou; 0 espelho funciona como uma heterotopia no sentido que ele torna esse lugar que ocupo, no momento em que me olho no espelho, ao mesmo tempo absolutamente real, em relação com todo o espaço que o envolve, e absolutamente irreal, já que ela é obrigada, para ser percebida, a passar por aquele ponto virtual que está lá longe. (FOUCAULT, 2001, p. 415)

O trecho acima destacado encontra-se no texto Outros espaços, conferência dada por Michel Foucault no Círculo de Estudos Arquitetônicos de 1964. Nela, o filósofo diz sonhar com uma ciência que teria por objeto espaços que se diferenciassem de todos os outros. Lugares fora do lugar, espaços diferentes, que tanto distanciam quanto colocam em disputa aquilo que conhecemos ou que acreditamos conhecer até então. Lugares que suspendem, neutralizam ou subvertem alocações, que abalam o pensamento propondo uma nova concepção de espaço ao denunciar o surrealismo presente no modo como geralmente classificamos as coisas.

Para desenvolver tal ideia, Foucault pensa primeiramente nas utopias, conceito criado por Thomas More e que traz a ideia de um lugar ou estado ideal, fantástico, cuja existência se

Poiésis, Niterói, v. 20, n. 33, jan./jun. 2019. 
faz somente na imaginação. Derivada da junção entre o prefixo de negação " $u$ " e da palavra "tópos", que, em grego, significa "lugar", a utopia seria um não-lugar, um lugar perfeito, idílico, que estancaria os buracos e as falhas do mundo real. Um lugar inexistente, assim como também as distopias, que, ao contrário da perfeição, vislumbrariam, em contrapartida, a pior versão de um mundo possível. Diferentemente de tais ideias, as heterotopias de que Foucault nos fala são lugares precisos, reais e localizáveis, lugares que existem, mas que estão em um espaço do "entre", em um limiar, sem palavra possível para defini-los. Lugares sem lugar, que não pertencem a lugar nenhum, e que

\section{inquietam, sem dúvida porque solapam secretamente a linguagem, porque impedem de nomear isto ou aquilo, porque fracionam os nomes comuns ou os emaranham, porque arruínam de antemão a "sintaxe", e não autorizam "manter juntos" (ao lado e em frente umas das outras) as palavras e as coisas. (FOUCAULT, 1987, p. 7)}

É importante dizer que as heterotopias de que Foucault nos fala não são necessariamente lugares topológicos, físicos, urbanísticos. São lugares qualitativos: podemos encontrá-los tanto em um espaço arquitetônico quanto em uma fotografia, em uma cadeira, ou até mesmo no ato de tomar uma xícara de chá. Elas devem ser compreendidas como um lugar outro, "uma espécie de contestação ao mesmo tempo mítica e real do espaço em que vivemos". (FOUCAULT, 2013, p. 20) São representações que confrontam a si mesmas e, ao se confrontar, provocam uma reflexão, permitindo um olhar crítico em relação a onde estamos, o que fazemos, como nos posicionamos. São ao mesmo tempo representação e não representação, passado e acontecimento, tédio e criação.

É possível pensar, a partir das ideias de Foucault, que são heterotopias não somente o espelho, como também as fotografias de Breder e Tochtrop. Do que vimos até aqui, elas remetem a um espaço ao mesmo tempo real e irreal. O passado, os dados memoriais fixados em imagem, junto ao inventado, ao criado, à expectativa, à potência, ao futuro, ao devir. São elas imagens de nuvem, aquosas, figuras do entre, retratos irretratáveis, fotografias do impossível. E mais do que isso. A partir de tais dizeres, podemos pensar 
não somente na possibilidade de associação entre tais fotografias e a ideia de heterotopia, como também na hipótese de uma intrínseca e necessária relação entre o conceito de heterotopia e o de limiar.

Resgatando aqui os escritos de Walter Benjamin (2006), o mesmo diz que o limiar é uma zona, ou, mais exatamente, uma zona de transição, de mudança, de fluxo. O limiar não significa propriamente a separação, como o faz o conceito de fronteira, mas indica um lugar e um tempo intermediários, e portanto, indeterminados. Por tal razão, o limiar não se inscreve dentro de uma lógica binária, do isso ou aquilo, mas, pelo contrário, refere-se a algo que é, ao mesmo tempo, isso e aquilo, caracterizando-se por um tipo de tensão próxima à figura do paradoxo.

Podemos compreender os limiares como zonas do "entre", locais não tão precisos quanto os outros, ou melhor, locais exatamente destinados à imprecisão. Territórios de - e para - desterritorializações, espaços que dão lugar aos estados de mudança, às flutuações, aos deslocamentos. (GAGNEBIN, 2010) Podem ser abordados como espaços de suspensão, de experimentação. Espaços de jogo, em que a indefinição e a ausência de fronteiras rígidas fazem com que a realidade possa tanto ser questionada - proporcionando em nós um estado de pensamento e de reflexão - quanto criada, demonstrando-se como um importante fator de transformação e de engendramento de novas realidades possíveis. Ou, por que não, de novos mundos, exatamente como parecem fazer as fotografias de Breder e Tochtrop.

Pensando nisso, uma imagem também complementa a discussão. É o cartaz da exposição Fotografia expandida, ocorrida entre os dias 20 de setembro e 13 de novembro de 2016 no Centro Cultural Oi Futuro do Flamengo, no Rio de Janeiro. Nele, há a reprodução praticamente idêntica ao original de uma das obras apresentadas na mostra. Sob curadoria de Alberto Saraiva, a exposição apresentou, em 20 obras estáticas ou interativas, o trabalho de pesquisa a respeito da imagem fotográfica produzido ao longo de 24 anos pela professora da Escola de Artes Visuais do Parque Lage e artista plástica Denise Cathilina. Em sua

Poiésis, Niterói, v. 20, n. 33, jan./jun. 2019. 
trajetória, foi interesse de Denise Cathilina a investigação dos limites e das possibilidades apresentadas pela fotografia, explorando-a para além de seus meios, de sua pretensa objetividade e de seus usos convencionais, comumente ligados ao registro e à representação. Em vez do gênero documental, portanto, Denise Cathilina voltou-se para a fotografia de experimentação ou, em outras palavras, para a fotografia-arte. Faz parte de seu trabalho, assim, obras produzidas a partir de negativos, imagens analógicas, digitais, câmeras de vigilância, cianotipias, fotografias impressas e virtuais, fotos $3 \times 4$, digitalizações e diversos outros suportes possíveis apresentados dentro desse campo.

O cartaz da exposição de Denise Cathilina - que é, também, a réplica de uma de suas obras - retrata, curiosamente, uma cadeira. A figura de uma cadeira, melhor dizendo, a reprodução da figura de uma cadeira. Mas a cadeira que se encontra no pôster da exposição de Denise Cathilina não é a reprodução de uma cadeira comum, apresentada nos mesmos moldes como a vemos cotidianamente, por exemplo, ao observar o ambiente de nossa sala de estar. Pelo contrário. A cadeira da artista é uma cadeira inusitada, singular, a nós somente reconhecível pelo contorno de suas formas, cujo interior compõe-se de uma densa massa branca. A cadeira de Denise Cathilina aparenta a figura de um raio- $x$, uma figura do "entre". Uma imagem que, ironicamente, mostrando um objeto para nós já habitual, nos apresenta, de outra forma, também algo a nós sem referência. Uma certa imagem de uma não-imagem; algo de invisível, finalmente visível. Por meio dela, a sensação que temos é a de que podemos enxergar o que há através, perceber o que cada uma de nossas cotidianas e banais cadeiras é capaz de nos esconder. Ver o que das cadeiras não conhecemos ou dominamos, ainda que o frequente contato em nosso dia a dia as tenha posicionado como algo trivial. A escolha da cadeira como material de investigação na obra de Denise Cathilina, por isso, não parece ter sido um fator aleatório. Ela traz a ideia de que, mesmo naquilo em que se acredita mais claro, determinado, definido para nós, existe a possibilidade de uma oscilação. Tratar-se-ia, então, da proposição de um lugar onde, apesar de tudo, o vago, o não sabido, o impreciso - ou até mesmo o ilimitado tenha espaço. Onde se possa, por assim dizer, apreender - e assumir - o indeterminado, deixando de evitá-lo para, enfim, abarcá-lo sem medo ou pudor. 


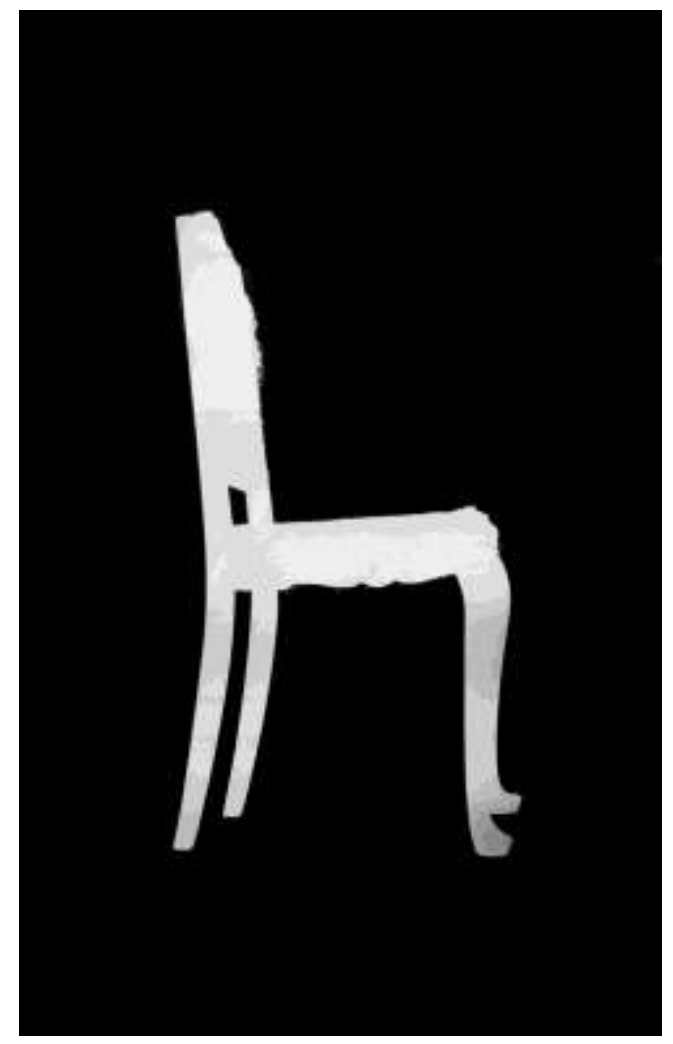

Fig. 5 - Denise Cathilina, Possível, 1999.

Poiésis, Niterói, v. 20, n. 33, jan./jun. 2019. 
Da mesma forma como ocorre com a cadeira de Denise Cathilina, ao vermos as outras fotografias de Breder e Tochtrop, em vez de guiarmos nosso olhar pelo que já nos é dado de reconhecível, definido, seguramente assimilável, as figuras distorcidas e enigmáticas que suas imagens nos apresentam fazem com que o estranhamento seja o primeiro sentimento produzido, fazendo-nos entrar em um estado de dúvida. Uma pergunta, então, inevitavelmente ocorre: o que é isso? Ao ver tais imagens, não conseguimos formular respostas nem certezas e, por vezes, o único conforto que somos capazes de vivenciar é quando as aceitamos em sua própria materialidade, em sua própria significância, para além do que poderiam ou mesmo gostariam - se é que gostariam - de representar. Se René Magritte e o surrealismo nos trouxeram à discussão os limites da representação com o famoso quadro Ceci n'est pas une pipe - ou, em português, Isto não é um cachimbo -, poderíamos, aqui, talvez acrescentar à frase um pequeno adendo: isso não é um cachimbo. Isso, justamente, é.

Tais fotografias inquietam, desafiam, provocam talvez pelo fato de nelas haver algo que jamais poderemos completamente compreender. Elas nos lançam em uma espécie de busca, mas uma busca particular. Uma busca infinita, interminável, aparentemente inútil, como a procurar por algo que sempre nos escapa, muito embora, curiosamente, esteja ali. Elas possuem uma quantidade de visões e opções interpretativas infinitas e poderíamos levar uma vida inteira a estudar cada uma delas, sem que, com isso, tivéssemos ainda capacidade de saber ao certo o que são, sobre o que falam, do que tratam exatamente. Vendo-as adentramos em um mundo confuso, nebuloso, misterioso e, ao mesmo tempo, muito próximo, em que a falta de um entendimento preciso não impede, contudo, de nelas querermos mergulhar. Ao mesmo tempo em que nos trazem um estranhamento, também nos dão uma curiosa sensação de presença, de tempo presente. Elas parecem produzir um estímulo, um despertar, uma repentina consciência que se demonstra tão excitante quanto vivaz.

Entrar em contato com elas nos leva a experimentá-las, atravessá-las, nelas imergir e com elas nos misturarmos, nos movimentarmos como em uma dança de sensações em 
que a inteligência por vezes falha. Poderíamos arriscarmo-nos a perguntar, então, se não seria essa justamente sua força, seu destino. Serem mesmo corpos indeterminados, inclassificáveis. Corpos abertos, inacabados, que nos mantêm em um estado de eterna suspensão, abrindo-nos a um universo de imaginação, reflexão e criação.

\section{Referências}

BACHELARD, Gaston. A água e os sonhos: ensaio sobre a imaginação da matéria. São Paulo: Martins Fontes, 1997.

BACHELARD, Gaston. O ar e os sonhos: ensaio sobre a imaginação do movimento. Tradução de Antônio de Pádua Danesi. São Paulo: Martins Fontes, 2001.

BENJAMIN, Walter. Passagens. Organização: Willi Bolle; Olgária Matos. Trad. Irene Aron; Cleonice Mourão. Belo Horizonte: Editora UFMG; São Paulo: Imprensa Oficial do Estado de São Paulo, 2006.

COHEN, Ethan. Hans Breder. Disponível em https://www.ecfa.com/hans-breder. Acesso em 28 dez. 2018.

FOUCAULT, Michel. As palavras e as coisas. São Paulo: Martins Fontes, 1987.

FOUCAULT, Michel. Outros espaços. In Ditos e escritos III: Estética: literatura e pintura, música e cinema. Rio de Janeiro: Forense, 2001.

FOUCAULT, Michel. O corpo utópico, as heterotopias. São Paulo: n-1 Edições, 2013.

GAGNEBIN, Jeane-Marie. Entre a vida e a morte. In OTTE, Goerg; SEDMAYER, Sabrina; CORNESEN, Elcio (Org.). Limiares e passagens em Walter Benjamin. Belo Horizonte: Editora UFMG, 2010.

GOMES, Marcelo. Gaston Bachelard: e a metapoética dos quatro elementos. Revista Estética, São Paulo, n. 11, ago-dez, 2015.

Poiésis, Niterói, v. 20, n. 33, jan./jun. 2019. 